\title{
Migraciones, causas y nuevas identidades
}

\author{
Dr. Ramón D. Rivas \\ Director \\ Dirección de Cultura, \\ Universidad Tecnológica de El Salvador \\ ramon.rivas@utec.edu.sv
}

\section{Resumen}

Este artículo demuestra que desde el génesis de la humanidad, las migraciones han sido, y seguirán siendo, un hecho social condicionado o provocado por diferentes factores humanos o de naturaleza ambiental, demográfica, económica, cultural, religiosa o sociopolítica.

El autor constata que la historia moderna nos demuestra que el fenómeno de las migraciones ha sido una opción para alcanzar mejores condiciones o formas de vida, o en muchas ocasiones han sido migraciones forzadas que generan una transformación traumática de la identidad, la cultura, las tradiciones y el desarrollo mismo de las personas.

Palabras claves: Migraciones, identidades, cultura, economía, política, destierro, etnicidad, tradiciones.

\begin{abstract}
This article shows that migrations- from the very beginning of humankind- have been and will continue being a social fact that is either conditioned or caused by a variety of human factors, or of an environmental, demographic, economic, cultural, religious or sociopolitical nature.

Its author proves that modern history demonstrates that the phenomena of migration has been an option to reach better lifestyles or living conditions; also, that in many other occasions, migrations have been forced hence generating a traumatic transformation of identity, culture, traditions and the development itself of the peoples.
\end{abstract}

Key words: Migrations, identities, culture, economics, politics, exile, ethnicity, traditions. 


\section{Planteamiento y descripción}

La migración forzada, vista desde la definición de la Organización Internacional para las Migraciones, es "la realizada por cualquier persona que emigra para escapar de la persecución, el conflicto, la represión, los desastres naturales y provocados por el hombre, la degradación ecológica u otras situaciones que ponen en peligro su existencia, su libertad o su forma de vida"; pero también es considerarla como el desarraigo de los habitantes de una tierra o de parte de ellos mediante su expulsión. Ejemplo de esto es la registrada en el año 2010 cuando en Francia se inició un proceso de expulsión de sus territorios de cientos de familias gitanas, argumentando que "eran europeos pero indocumentados". Fueron otras las razones que provocaron esta expulsión, que no mencionaré aquí por no ser parte del tema. El hecho resultó indignante, ya que la deportación de gitanos inmigrantes provenientes de Rumania y Bulgaria provocó en estas personas un rompimiento de su estabilidad familiar, psicológica y económica.

Esta misma situación han vivido miles de latinos radicado en países como Estados Unidos de Norteamérica y Canadá. El primero experimentó, a principios de la década de los años 70 , una oleada de inmigrantes latinos, que con los años se fue incrementando por las luchas sociales que se libraron en esa época y por las catástrofes naturales que golpearon a muchos países del continente entonces. Hoy en día, los Estados Unidos han iniciado una política de expulsión forzada de cientos de miles de latinos "indocumentados", argumentando que estos han violentado sus leyes de inmigración o cometido ilícitos durante su estadía en su territorio.

Lo grave en todo esto es que muchas personas que tenían años de haber permanecido en esos países fueron separadas de sus familias, de sus viviendas y de sus empleos. Tenían que regresar a sus tierras de origen en búsqueda de mejores condiciones de vida. Indudablemente, los seis años fiscales de la Administración del presidente Barack Obama rompió cuatro récords sucesivamente de expulsiones, sumando más de 1.5 millones de inmigrantes deportados, generando con ello una crisis social y económica en los países de origen de esos inmigrantes.

Pese a esta política, datos del 2009 de la Oficina del Censo de los Estados Unidos indican que este país registraba en ese año más de 36.7 millones de personas nacidas en otros países; muchos de ellos son ciudadanos naturalizados de los Estados Unidos y otros millones son residentes permanentes legales. No obstante, aún falta por legalizar a 12 millones de personas que llegaron y se quedaron a vivir de forma ilegal en el país, sin que a la fecha se vislumbre una medida política que logre legalizarlos y así poder salir del anonimato jurídico en el que se encuentran.

Históricamente, El Salvador es un país que ha registrado migraciones permanentes, algunas de carácter forzados, y otras provocadas por el conflicto 
armado y por la crítica situación socioeconómica y laboral por la que ha atravesado el país en las últimas cuatro décadas. Muchos emigraron a países como Honduras, Panamá, Estados Unidos, Arabia Saudita, entre otros, dejando su patria para aventurarse en otras tierras, aunque tendrían que sufrir agravios y pesares, tal como los describe Roque Dalton en su estremecedor "Poema de Amor" en el que habla sobre los eternos indocumentados.

Pero también tenemos los conflictos que se libraron en la penínzula de los Balcanes, desde los años de 1912 al 2001, vinculados con los sentimientos nacionalistas entre croatas y serbios, la independencia de Bosnia-Herzegovina, la guerra del Kosovo, y a otras causas sociales, económicas, culturales, religiosas y étnicas, que provocaron una serie de oleadas de migrantes en búsqueda de nuevos horizontes en paz y libertad. Esta guerra, - que según algunos historiadores fue una guerra civil muy particular ya que no se trataba de facciones de un mismo pueblo que se enfrentaban a otras, sino de pueblos que fueron obligados a vivir dentro de las fronteras de un Estado creado artificialmente - dejó serias heridas entre los grupos étnicos serbios, croatas y musulmanes que combatieron entre sí para lograr establecerse en sus tierras.

Es importante señalar que los movimientos migratorios en el mundo han sido parte de la historia misma de la humanidad; unas voluntarias y otras forzadas. Aunque las características de las migraciones actuales comparadas a las de las anteriores puedan ser similares, es importante señalar que hoy en día este fenómeno social está provocando serios problemas a nuestros países, culturas, e identidades, y sobre todo a nuestra concepción de familia o grupo social.

El ser humano, por naturaleza, tiene un instinto gregario que lo lleva a proteger su patrimonio, sus valores, tradiciones y su territorio. Pero ese instinto gregario puede, de alguna manera, perderse o transformarse, dependiendo de las condiciones sociales en las que viven las personas y que las motivan a abandonar a su "manada", a su gente con su cultura y tradiciones. Ejemplo de ello lo constituye El Salvador, en el cual las migraciones han trastocado hasta lo más íntimo del concatenado social, que es la misma familia. Esto no va a hacer que la cultura desaparezca, porque no desaparecerá nunca, pero la cultura se transforma, y, en este caso, se transforma no para bien, sino para degenerar la sociedad, el mismísimo tejido social, presentando patologías muchas veces fuera del alcance de la comprensión del ser humano.

Este artículo se basa no solo en aspectos teóricos y casos estudiados y analizados, es parte también de la experiencia vista como antropólogo y migrante salvadoreño al tener que vivir desde muy joven en países como Guatemala, Nicaragua, Honduras y Holanda. En fin, considero que existen los elementos suficientes para conocer e interpretar el sentimiento humano que se vive como inmigrante lejos de su tierra natal y como antropólogo que busca una explicación científica a este fenómeno social propio de la naturaleza humana y encontrar la respuesta. 
De ahí que presento este tema desde dos dimensiones académicas: la Antropología sociocultural y la Antropología estructural. Para iniciar con el tema "Migraciones, causas, y nuevas identidades" partiré de los siguientes interrogantes: ¿cómo afectan las migraciones a las sociedades modernas? ¿qué tipo de cultura se forma en América con las migraciones mundiales? y ¿cuál podría ser el futuro identitario de América con las constantes migraciones de sus pueblos?

\section{Las migraciones desde el enfoque antropológico}

Es importante señalar que la Antropología es una ciencia muy útil para conocer e interpretar las formas de vida del ser humano y su incidencia en el contexto social. A la fecha existen muchos aportes teóricos e investigaciones científicas de lo que la Antropología ha hecho en favore de las sociedades modernas, y que pueden servir de insumos para impulsar políticas de desarrollo de nuestros pueblos. En lo personal, traeré a cuenta los aportes de grandes antropólogos que sentaron las bases para estudiar al ser humano desde una visión diferente a las otras ciencias.

Considero necesario acudir a los fundamentos de la Antropología porque es ahí donde podemos encontrar respuestas a problemas tan serios como es la migración de las personas por la búsqueda de mejores oportunidades de desarrollo, por obtener los recursos y servicios básicos que sus países no les han provisto. Quizá algunos colegas prefieran citar o interpretar los hechos humanos desde las nuevas teorías antropológicas. No obstante, como el fenómeno migratorio de los seres humanos es ancestral, me permitiré acudir a los fundamentos teóricos hechos por Lewis Henry Morgan, considerado como uno de los auténticos padres de la Antropología moderna y que ha aportado mucho a la sociedad con sus diferentes teorías, las cuales, de ser aplicadas, nos permitirían mejores resultados en la interpretación de los problemas, pensamientos y actitudes de los salvadoreños.

También destacan en la academia los aportes de Georges Louis Leclerc, conde de Buffon; Herbert Spencer, quien fue una figura muy respetable en el ámbito científico y que expuso sus teorías apoyándose en las leyes naturales; Halse Rivers, Edith Turner, Clifford Geertz, Sherry Ortner y Ulf Hannerz, entre muchos más. Lo importante en todo caso es dar una aportación antropológica a las permanentes corrientes migratorias, $\mathrm{y}$ - como lo dice Manuel Oliver Narbonaeste aporte debe partir de "la visión que da la perspectiva antropológica, de que toda cultura designa el patrimonio social de los grupos humanos, y que puede comprender todo tipo de conocimientos, creencias, normas, valores, símbolos e ideologías, conformando un sistema de comportamientos que serán y son transmitidos generacionalmente".

Cada uno de los autores que he citado ha estudiado a los seres humanos y sus relaciones sociales desde diferentes enfoques y pensamientos filosóficos. Sus 
enfoques pueden ayudar a interpretar a partir una visión holística el fenómeno de la migración humana y sus implicaciones en el desarrollo social y cultural de las personas.

Según esa perspectiva, tomaré algunos conceptos de la Antropología sociocultural para estudiar al ser humano desde la concepción de que este forma parte de un grupo social y de que es integrante de una cultura. La parte central de este enfoque antropológico es que la cultura proporciona a los grupos humanos una imagen o, — si se quiere - , una identidad. Así mismo, Edward Tylor añade que la cultura es "ese todo complejo que incluye el conocimiento, las creencias, el arte, la moral, el derecho, la costumbre y cualesquiera otros hábitos y capacidades adquiridos por el hombre como miembro de la sociedad".

Desde este enfoque, tenemos que considerar las graves implicaciones sociales $\mathrm{y}$ culturales que tienen los movimientos migratorios, cuando las personas abandonan su lugar de origen para alcanzar mejores formas de vida, ya sea por, necesidad o preservación de su vida ante una amenaza determinada o por ilusión. Es decir, el choque cultural que debe enfrentar una persona cuando sale de un grupo social para integrarse a otro puede, en alguna medida, afectar su identidad, la cual Tylor describe en su definición de identidad cultural.

Ese choque cultural que enfrentan hoy en día las personas que tienen que migrar a otros países o ciudades les transforma su espíritu identitario, su naturalidad cultural y hasta sus creencias y derechos que tienen como seres humanos.

Como muy bien lo describe Iain Chambers: "La migración implica un movimiento en el que el lugar de partida y el punto de llegada no son inmutables ni seguros. Exige vivir en lenguas, historias e identidades que están sometidas a una constante mutación". Pero esta mutación es constante y muchas veces triste al observar cómo transforma al ser humano en una persona sin un origen y sin una identidad con la cual se sienta segura y hasta orgullosa. Como lo mencioné al principio, yo he sido inmigrante por años y he tenido que sufrir pena ajena por la experiencia de hermanos salvadoreños avergonzados de sus orígenes y hasta de su propia forma de hablar. En muchas ocasiones nuestros compatriotas - y no solo de El Salvador, sino que de otros países - prefieren adoptar el acento y parte del lenguaje de personas que si tienen raíces culturales muy arraigadas, como de los mexicanos. Muchos terminan hablando como argentinos o cubanos. $\mathrm{O}$, en el mejor de los casos, hablan como salvadoreños pero con modismos extranjeros.

Lo que sucede es que, la identidad tiene como elementos el reconocimiento o la sanción del otro y la pertenencia a una pluralidad de colectivos. Sin estos dos elementos, la persona queda excluida del grupo y puede, en alguna medida, deformar su personalidad hasta llevarlo a convertirse en alguien que construye su propia identidad sobre la base de valores contrarios a los de su grupo social. Ejemplo de esto son las pandillas que hoy agobian a nuestra región americana. 


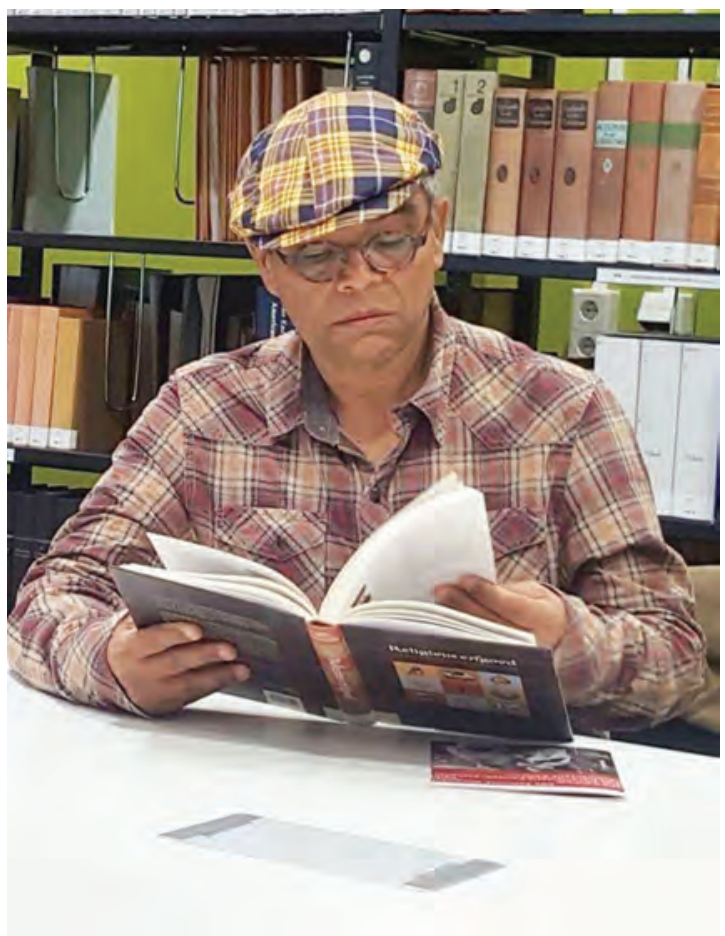

Dr. Ramón D. Rivas

Con lo anterior quiero dejar en claro que el fenómeno migratorio tiene un impacto negativo en nuestra gente. Se adoptan costumbres y modos de vida fuera de su patrón cultural originario. Se llega a creer que se es más ciudadano en el país al que se migró que del que salió. Se cambian hasta los patrones alimenticios, el gusto musical y hasta se ejerce una fuerte influencia en el grupo de origen o familiares para que adopte las nuevas costumbres del país donde se radica como inmigrante, legal o ilegal. De ahí que no es extraño que cuando se pregunta en Centroamérica por los familiares inmigrantes que viven en los Estados Unidos, muchos se expresan con orgullo que sus familiares son ciudadanos o residentes legales norteamericanos.

El estatus de haber migrado a ese país los hace sentir orgullosos de su familiar inmigrante porque lo convierte en un ejemplo de superación. Muchos familiares de los inmigrantes se sienten hasta superiores por el simple hecho de tener familias en la gran nación del Norte; y sin haber viajado o vivido en ese país promueven sus costumbres, tradiciones y fiestas nacionales, como celebrar el "Día de la independencia" el 4 de julio, el Thanks Given y otras más, como si estas fueran costumbres propias de nuestras culturas maya, inca, lenca o azteca.

Esto debe preocupar a la academia y a organizaciones mundiales como la Unesco, la cual declaró en París, en el 2001, que "cada cultura se nutre de 
sus raíces pero sólo se desarrolla en contacto con las demás". Si esto es así, entonces ¿qué tipo de cultura estamos desarrollando cuando sus miembros mutan permanentemente su identidad? ¿qué tipo de sociedad se está construyendo si sus raíces culturales están cada día más desvanecidas? Esto es preocupante, porque, al perderse las raíces de nuestras culturas y persisto en una constante mutación de la identidad, entonces se puede asegurar que tenemos seres huecos culturalmente; deformes en su identidad y propensos a la autodestrucción como hombres y mujeres sociales, gregarios y con valores. Esto podría ser uno de los tantos factores del origen de grupos irregulares como las pandillas y de personas que se dedican a delinquir mediante narcotráfico y el sicariato, por ejemplo.

Este fenómeno social probablemente no se experimentó en las migraciones hechas por las tribus o personas de la prehistoria, ya que ellos se movilizaban en grupos o tribus completas con el fin de protegerse de la amenaza de otros clanes, o sencillamente para subsistir juntos y conservar a sus mujeres e hijos con sus respectivas costumbres y valores.

En los tiempos modernos prevalece más la migración individual, característica que debe ser analizada por los académicos y científicos del mundo, ya que esto podría ser motivado por aspectos sociales que le afectan en su desarrollo personal o familiar. Las mismas leyes particularizan la migración y califican a cada uno de ellos como migrantes ilegales o legales, inmigrante en búsqueda de asilo político o refugiados que huyen de sus países por miedo a la persecución religiosa, racial, política y violencia generalizada en sus lugares de origen, como es el caso de nuestro país, El Salvador.

La clasificación que de ellas se haga no es tema de este artículo. Lo que sí es importante reiterar son los daños que la migración causa en el ámbito identitario al llegar a otras naciones que no sea las de origen. Esto genera un impacto social con connotaciones negativas, que en el los académicos, científicos, investigadores sociales y formuladores de políticas públicas debemos reflexionar para encontrar y proponer políticas de solución a esta consecuencia sociocultural.

Ya existen investigaciones locales que se realizan en algunos países, como México, donde la tasa de migración es muy alta, seguido de El Salvador, Guatemala y Honduras, entre otros. Estos países sufren de una transformación sociocultural que incide en los comportamientos sociales e institucionales y por ende culturales, así como en los elementos de cohesión comunitaria. ¿A qué me refiero? A esos cambios que se están registrando en nuestras poblaciones, como producto del cruce de culturas, o a la adopción de nuevos patrones culturales que afectan a nuestros grupos de origen o a los grupos sociales donde nos insertamos como inmigrantes.

Como muy bien lo señala Jorge Mercado Mondragón en su estudio relacionado con las consecuencias culturales de la migración, este fenómeno social debe 
ser analizado cuidadosamente porque tiene repercusiones "en el idioma, en la conformación de nuevas estructuras económicas, en las nuevas pautas de reproducción, en los nuevos lugares de reproducción de patrones socioculturales, en los sistemas de cargos, en la vida ceremonial, en los sistemas agrícolas, en la organización del trabajo agrícola, en la estructura familiar, en las redes de relaciones sociales, en la educación, en la organización comunal y en el ámbito simbólico".

Estos cambios socioculturales —entendido este como aquel que se produce y lleva a cabo en el nivel de los símbolos culturalmente significativos que el hombre produce - están registrándose tanto en los países que son receptores de los inmigrantes como en aquellos que exportan a las personas para que busquen nuevas oportunidades y generen con ello remesas que contribuyan a las alicaídas economías latinoamericanas.

\section{La inminente transformación las identidades culturales americanas}

El laureado escritor mexicano Carlos Fuentes expresó en el VII Foro de Iberoamérica que "nuestro privilegio, nuestra personalidad iberoamericana, es indígena, africana, mulata, mestiza y, a través de Iberia, mediterránea, griega, latina, árabe, judía, cristiana y laica. Todo ello nos convierte en el espacio privilegiado, de Yucatán a Andalucía y de Minas Gerais al Algarve, para dialogar con los demás, que nunca serán los que sobran, los de menos, sino los que aún no abrazamos, los demás. Somos — podemos ser- el microcosmos de la convivencia". La anterior afirmación debe llevarnos a reflexionar sobre la gran diversidad cultural con la que cuenta Iberoamérica, una región de más de 600 millones de habitantes que han sabido sobrevivir e integrarse a otras culturas que incursionaron, o invadieron, en nuestro continente.

Pero esa diversidad cultural, de la cual habla Fuentes, se podría entrar en una lucha campal por la hegemonía del poder. Por ejemplo, las culturas originarias están amenazadas por la amorfa identidad cultural que les invade al introducirse en ellas personas que adoptan y promueven patrones culturales transnacionales. No es extraño así que la identidad cultural de nuestros pueblos originarios sea la que podría desaparecer por la fuerte transculturización que arrasa con las manifestaciones culturales y la creación artística de nuestra gente.

Aunque la presencia de otras culturas ha sido un hecho histórico en esta región - y que "celebramos" con fiestas nacionales por la integración de la cultura de los españoles a nuestras tierras, de los portugueses e ingleses - , lo cierto es que nuestras raíces indígenas o de pueblos originarios aún sobreviven, pese a la ruptura cultural que se provocó con las conquistas realizadas. No obstante, nuestras raíces podrían desaparecer en los próximos años si no ponemos un freno a los daños colaterales que están causando las migraciones a países con fuerte influencia cultural. 
No podemos hablar de diversidad cultural partiendo solo de las culturas que se integraron en nuestro continente en épocas anteriores. Se debe incluir también la cultura que hicieron florecer a América antes de las conquistas de los europeos. Debemos proteger nuestras raíces culturales y las que se han integrado después de la migración de europeos a la región americana, fortaleciendo la institucionalidad de cada país, a fin de crear normas y leyes que protejan la diversidad cultural de la región.

Con lo anterior no quiero imponer un revanchismo cultural en la región; sino, al contrario, quiero instar a que reflexionemos sobre la importancia y riqueza cultural que tenemos y que se genera en los territorios de destino con los movimientos de personas. Es decir, debemos aprovechar las migraciones como un medio para fortalecer nuestras culturas, intercambiar valores y disfrutar de esa riqueza cultural y artística que se genera en cada pueblo o nación. Ninguna cultura debería desplazar a otra. Al contrario, debemos buscar los mecanismos sociales para integrar la cultura de los grupos de inmigrantes a fin de engrandecer la diversidad cultural de la región y aprovecharla como una oportunidad de crecimiento y desarrollo de los pueblos.

Las migraciones son un hecho que no podemos detener, pero sí podemos controlar $\mathrm{y}$ conducir socialmente. El problema es que hemos visto a las migraciones como un hecho social que favorece solo el aspecto económico, del cual hablaré más adelante. Tenemos que abrirnos más a ver este fenómeno como un hecho social que puede enriquecer nuestra cultura más que desplazarla. Los académicos y científicos no podemos pasar inadvertido este tema o encerrarnos en discusiones estériles. Como lo dijo otro escritor mexicano, Octavio Paz: "Si nos encerramos en nosotros mismos, hacemos más profunda y exacerbada la conciencia de todo lo que nos separa, nos aísla y nos distingue. Y nuestra soledad aumenta...”.

\section{Las oportunidades culturales que ofrecen las migraciones}

Ahora bien, ¿cómo aprovechar el fenómeno migratorio de la región americana? Culturalmente debemos promover el respeto, la difusión y conservación de las raíces culturales de las personas. Las migraciones no deben ser sinónimo de ruptura cultural, sino de integración cultural. Es una realidad que a la fecha muy poco se ha hecho por evitar las rupturas culturales; casi siempre los gobiernos se enfocan en tratar el tema migratorio como un fenómeno que persigue la subsistencia económica de la familia, el desarrollo profesional o la búsqueda de servicios y derechos políticos no satisfechos en los países de origen.

No obstante, si abordamos el tema desde el enfoque antropológico sociocultural, podemos encontrar formas o mecanismos de integración de las culturas, logrando con ello llevar oportunidades que favorezcan a las sociedades que reciben y envían personas como migrantes. Recordemos que en los años 60 y 70 las migraciones a otros países eran temporales, entendiendo por temporal como cuando las personas viajaban antes solo por unos años para dedicarse a 
las oportunidades de trabajo y luego regresar a sus países de origen. Ejemplo de ello es el flujo migratorio controlado que se dio durante la Segunda Guerra Mundial cuando los Estados Unidos de Norteamérica promovió la contratación de obreros y operarios salvadoreños para ampliar el Canal de Panamá y para reparar las bases de la Flota del Pacífico del Ejército de los Estados Unidos, en California, que se encontraba en guerra contra los países del Eje (Japón, Alemania e Italia).

A mediados de la década de los 70 del siglo pasado, se contrataron numerosos obreros y operarios salvadoreños para ir a trabajar a Arabia Saudita. Muchos de esos compatriotas buscaron quedarse en esos países y otros regresaron al país.

Hoy en día, en pleno siglo XXI, las migraciones de las personas a otros países son permanentes, es decir, son para establecerse en una nueva sociedad, para adoptar una nueva lengua y nuevas formas de vida. Ahí llegarán para buscar la integración social y los derechos políticos, tengan o no tengan trabajo. Se establecen con sus costumbres, religiones, valores y formas de vida. Buscan la integración social en un país que no conocen, que tiene diferencias culturales abismales y en donde prevalecen valores morales y humanos muy diferentes a los de su grupo de origen.

Ya hablamos de cómo este fenómeno social podría causar en la persona la transformación de su identidad y de su cultura si el grupo al cual se quiere integrar no lo acepta; o peor, si la persona inmigrante no tiene una fuerte identidad cultural con su pasado, lo cual puede llevar a adoptar una identidad a la cual no pertenece.

No obstante, si los gobiernos aprovecharan las migraciones como factor de integración cultural, se puede promover valores de convivencia e interacción para intercambiar aspectos culturales que ayudarían a la construcción de una sociedad más incluyente, más tolerante y más respetuosa de los derechos civiles. Quizá guste a algunos y moleste a otros, pero un ejemplo de lo que he mencionado anteriormente en este artículo lo representa los Estados Unidos de Norteamérica, Francia, Inglaterra y España. En el primer país, que forma parte de América, confluyen una serie de culturas que ha logrado integrarse y respetarse relativamente. Richard Pells, un su artículo titulado “¿Existe el McMundo?”, señala que "la cultura norteamericana es un ejemplo del enriquecimiento cultural debido a la acción de influencias extranjeras".

Contrario a la idea del "imperialismo cultural", Pells afirma que el éxito y el impacto mundial de la cultura norteamericana se basan en que, al ser un país de inmigrantes desde sus orígenes, la cultura estadunidense ha recibido, a través de las migraciones, influencias extranjeras de todo tipo, académicas, artísticas, intelectuales, que se reflejan en todas las formas de cultura popular: música, cine, literatura, televisión, etcétera. 
La anterior aseveración busca justificar la fortaleza multicultural que ha construido esa nación de inmigrantes en los últimos años, y que ha tenido gran influencia en los países de la región. La adopción que han hecho muchos países centroamericanos, y algunos sudamericanos, de la cultura estadunidense es producto de esa dependencia política y económica que se tiene con la unión Americana. De ahí que Pell sostiene que "la dependencia de los Estados Unidos respecto a las culturas extranjeras nos ha convertido en una réplica del mundo".

No obstante, esta visión resulta para muchos un poco idealizada, ya que no incluye los problemas que enfrentan los inmigrantes al momento de buscar la integración social y la adaptación cultural en ese país del Norte. Sin embargo, considero que se puede analizar este caso desde los aportes positivos que hace a la integración cultural. Así mismo, la presencia de otras culturas en una región determinada ayuda a construir normativas que promuevan la integración de los inmigrantes a las esferas sociales y culturales de los países, teniendo claro que deben reformularse las políticas públicas que precisen el reconocimiento y el respeto a su identidad cultural.

Pero también debe haber normas que obliguen a los inmigrantes a respetar y reconocer las culturas y tradiciones de las sociedades de acogida, a fin de armonizar y enriquecer la diversidad cultural de la cual hablé atrás. Esta es la tarea en la que se debaten naciones como Estados Unidos y Canadá. El primero cobijó a inmigrantes para alcanzar el éxito económico y social, pero en la actualidad debe replantearse su política de inmigración, ya que los permanentes cambios que esta produce pueden ser desestabilizadores y disgregadores sociales y con grandes repercusiones políticas, económicas y sociales.

Reitero en este apartado de mi reflexión sobre la inmigración. El reto para los gobiernos de América es buscar políticas públicas y normativas legales que promuevan la integración de los grupos de inmigrantes a las esferas sociales de los países receptores. Es una tarea muy difícil en la parte económica de los países, ya que estos tienen que buscar los medios para poder brindar servicios básicos como educación, salud, empleo y seguridad social para cada inmigrante legalizado. Pero también debe haber integración a la diversidad cultural, al respeto mutuo de sus derechos y costumbres, al desarrollo de su identidad cultural y pleno ejercicio de sus costumbres y tradiciones. Esos son los retos que hoy enfrentamos y considero que no son temas de fácil solución.

\section{Las migraciones desde una dimensión estructural}

Al inicio de este artículo señalé que existen dos formas de analizar las causas del fenómeno de las migraciones en el mundo académico: Desde las dimensiones antropológica y estructural.

Existe un postulado de Ravenstein (1889) denominado Histórico-Estructural que trata de explicar las migraciones basándose en las grandes diferencias 
económicas e históricas que median entre los países de procedencia y los de destino. En otras palabras, la teoría histórico-estructural afirma que las migraciones se producen desde los países que han sido colonizados, o se han visto afectados por la economía de un país más poderoso, a los países metropolitanos. Este planteamiento podemos acompañarlo con la teoría de la interdependencia, alimentada por el concepto de la globalización de las economías y hasta de las culturas e identidades.

Aunque no entraré en mayores detalles sobre estas teorías, considero importante que analicemos el fenómeno migratorio como resultado de la lucha hegemónica que históricamente han vivido las sociedades modernas. Y, cuando hablo de hegemonía, me refiero a la lucha existente hoy en día por el poder político, ideológico y económico que ejercen o han ejercido sobre los territorios, con la cual existe una interdependencia política y económica.

Por ejemplo, investigadores como Adolfo Albo y Juan Luis Ordaz Díaz, quienes analizaron en el 2011 los determinantes de la migración y los factores de la expulsión de la migración mexicana hacia el exterior, encontraron que millones de inmigrantes del mundo ven a los Estados Unidos, a la Federación Rusa, a Alemania, Arabia Saudita, Canadá, Francia, al Reino Unido y a España como los países que pueden ofrecerles mejores condiciones laborales y económicas. ¿Por qué? La respuesta está en que estos países ejercieron un poder hegemónico sobre el resto de naciones con las cuales mantienen o mantenían una interdependencia política, concebida esta por Keohane y Nye como una relación recíproca con profundos intereses internos, transnacionales y gubernamentales.

Veamos otros ejemplos: la India, con un pasado colonial. Las migraciones que se producen desde la India enfocan su mirada a Inglaterra. Lo mismo ocurre con Argelia y Marruecos, que normalmente tienden a migrar hacia Francia, país que ejerció su poder político sobre estos por muchos años. Otro ejemplo lo constituye Indonesia, cuyos emigrantes se van en su mayoría a Holanda, país que los colonizó por muchos años. En América las migraciones de mexicanos, centroamericanos y colombianos se dirigen hacia Los Estados Unidos, país que ha ejercido una hegemonía política sobre los diversos gobiernos de turno de dichos países.

Sin temor a equivocarme, considero que la intervención de los Estados Unidos en las estructuras económica y agraria en la región mesoamericana fue el detonante para que se incrementara el flujo de personas a la región norteamericana en búsqueda de una solución a sus problemas sociales y económicos. Pero también considero correcto el planteamiento de otras teorías que sostienen que son las condiciones de los países de origen las que empujan a las personas a migrar a otras naciones. Lo que habría que estudiar es las causas que provocan la migración en cada país, ya sea desde la visión antropológica sociocultural o desde la dimensión histórico-estructural, la cual nos da una visión amplia del 
fenómeno migratorio que se agudiza a pleno siglo XXI. En conclusión a esta teoría podemos asegurar que las migraciones deben analizarse desde su historia, como herederos de una gran historia, pero también como alguien a quien le van a reclamar la herencia los que vengan después.

Otro de los aspectos teóricos en la dimensión estructural está relacionada con la segmentación laboral que se implementan en los países donde mayormente se produce la migración de sus ciudadanos. La teoría de la segmentación del mercado laboral establece que no todo el mundo puede ir a cualquier nivel del mercado de trabajo.

Esta teoría divide al sector laboral en dos: primario, donde las oportunidades de empleo son buenos y adonde todo el mundo querría ir, y secundario, en el que lo que se ofrece son empleos precarios, mal pagados, dificultosos, e incluso peligrosos, que no son cubiertos por los nativos de los países que reciben migraciones.

Lo anterior genera tierra fértil para que los sistemas laborales de un país tiendan a contratar a migrantes ilegales, para que puedan realizar los trabajos no deseados por los nativos; mientras que, si las oportunidades son buenas, existe la posibilidad de que sea el mismo país el que ofrezca visas de inmigrantes para obtener esas ofertas de trabajo fuera de sus países de origen.

El último censo del 2010 elaborado por los Estados Unidos señala que los trabajadores centroamericanos se ubican, mucho más que el promedio de los latinos, en los sectores de la construcción y mantenimiento (20 versus $14 \%$ ) y la producción (12 versus 8,6\%). El $31 \%$ que trabaja en servicios lo hace fundamentalmente en la limpieza. En cambio, tienen menos presencia en los trabajos profesionales: 10,6 versus $19 \%$ del promedio de los latinos, el $31 \%$ de los cubanos y el $27 \%$ de sudamericanos y puertorriqueños.

Esta situación ocurre tanto en países de Europa como en Estados Unidos y Canadá. Muchos de los migrantes tienen que conformarse con actividades laborales relacionadas con el cuidado de personas adultas o niños; recoger las cosechas o dedicarse a trabajos agrícolas que no quieren realizar las personas nativas. Quienes mantienen la teoría de la segmentación del mercado laboral sostienen que el efecto llamada es lo que atrae a los inmigrantes, llegando con ello a ocupar los trabajos del sector secundario.

No entraré a describir otras teorías que explican el fenómeno migratorio del siglo XXI. Lo que sí es importante señalar en todo este análisis hecho hasta este momento son las múltiples formas de estudiar el caso que afecta nuestras identidades culturales. Como muy bien lo dice el tema que nos ocupa, las migraciones pueden generar nuevas identidades o transformar las culturas de nuestros pueblos. 
Para concluir, y a manera de resumen, responderé brevemente las preguntas que planteé al inicio las cuales repito:

\section{¿Cómo afectan las migraciones a las sociedades modernas?}

Socialmente causan deformaciones en las culturas, trastocan la identidad de los pueblos y demandan de nuevas políticas públicas y leyes que protejan la diversidad cultural que se registra en los países donde la sociedad está estructurada por diferentes culturas.

Además, genera luchas por territorios, luchas para mantener un sistema político determinado, confrontaciones ideológicas y choques de identidades que causan graves daños psicológicos a las personas. Y cuando se da la lucha por territorios se puede llegar al el etnocentrismo, el cual es uno de los grandes males que nos afectan para la comprensión de la diversidad cultural y para una convivencia humana sin enfrentamientos.

\section{¿Qué tipo de cultura se forma en América con las migraciones mundiales?}

Entonces, desde una perspectiva antropológica, considero que la diversidad cultural en América es la mayor riqueza de esta región. Lo que debemos hacer hoy es buscar la integración y preservación de nuestras raíces culturales sin importar la zona geográfica donde los encontremos. Los motivos para emigrar son muchos, pero eso no debe generar abandono de las raíces culturales que adquirió en su tierra natal; estas deben conservarse para poder mantenerse socialmente en cualquier parte del mundo donde nos radiquemos. Traigo a la mente las palabras de Mandianes (1993), cuando dijo: "El inmigrante gana libertad al dejar de ser controlado por su grupo, pero pierde los puntos de referencia que le dan sentido". De ahí que se deben crear mecanismos para que el inmigrante no pierda sus referentes culturales y pueda recomponer sus estructuras simbólicas, siempre que su capacidad le permita hacerlo. Debemos, en pocas palabras, construir una cultura de integración, de inclusión y de solidaridad con el inmigrante.

Hoy en día las diferencias culturales son una de las graves dificultades con que se encuentra el hecho migratorio. La intolerancia que genera "solamente puede superarse a medio o largo plazo con cambios radicales en la educación de los ciudadanos: una educación basada en un concepto plural de la ciudadanía" (Pujadas, 1993).

\section{¿Cuál podría ser el futuro identitario de América con las constantes migraciones de sus pueblos?}

Debo recordar que un país no es homogéneo, y por lógica una región no podrá ser homogénea, desde el punto de vista identitario y cultural. Cuando hemos hablado de la transformación cultural como causa de las migraciones, nos debe 
llevar a pensar que se están originando, evidentemente, nuevas identidades en el imaginario mundial.

Probablemente sean identidades culturales más individualistas, basados en principios que contradigan a la cultura de paz y convivencia pacífica, o identidades transnacionales con visiones del mundo diferentes y necesidades diferentes.

De ahí la importancia de la conformación de un instituto para las investigaciones científicas en cada uno de los países, para que se enfoque directamente al estudio de la migración desde perspectivas psicológica, económica, antropológica, cultural, política e histórica.

Por ejemplo, en El Salvador se necesita hacer profundos estudios sicológicos y sociológicos que nos expliquen fenómenos psicosociales como el de las maras, el bilingüismo, la aculturación, el narcotráfico, la emigración forzada, la ruptura del núcleo familiar, el bigamismo, la sed consumista o el surgimiento y auge de productos nostálgicos en los Estados Unidos, como el Pollo Campero; los refrescos naturales salvadoreños como el de carao, tamarindo, el "agua dulce", las conservas de coco, las melcochas, entre otras.

Y ello habla también de nuevos valores y de nuevas identidades tanto para los actuales residentes salvadoreños en el exterior como para la nueva generación de descendientes de compatriotas en los Estados Unidos y en el resto del mundo.

\section{Conclusiones}

A manera de resumen, concluyo con que se requiere de un organismo científicoacadémico especializado que estudie las raíces de la actual problemática, que propugne soluciones viables y que realice no solo el diagnóstico sino también las propuestas de solución a todo el entramado global del fenómeno de la migración, las nuevas identidades, las nuevas realidades y los nuevos paradigmas que aquel fenómeno conlleva para los países que exportan a su gente hacia otras naciones del mundo.

También es necesario adoptar nuevos enfoques de la inmigración para abordar la sensación de crisis que enfrentan los países que reciben a los migrantes provenientes de diferentes partes del mundo. Hay que replantear las políticas públicas sobre la inmigración y las oportunidades que ofrece esta a los países en una nueva era. Es un hecho social que se ha mantenido permanente en las últimas décadas. Ante esa realidad, se necesita atenderla. 


\section{Referentes bibliográficos}

Adolfo Albo y Juan Luis Ordaz Díaz. "Los determinantes de la migración y factores de la expulsión de la migración mexicana hacia el exterior, evidencia municipal". Número 11/04, México, febrero 2011.

Camila Aviña Zavala. "La migración como factor de enriquecimiento cultural".

Cultura y Migraciones. Organización de Estados Iberoamericanos para la Educación, la Ciencia y la Cultura (OEI). /www.oei.es/catalogoartistas/ index.php.

Ernest Cañada. "Migraciones en Centroamérica: en la médula de un cambio estructural". Revista Académica de la Universidad Centroamericana. Encuentro. 2011.

Jorge Mercado Mondragón. "Las consecuencias culturales de la migración y cambio Identitario en una comunidad Tzotzil", Zinacantán, Chiapas, México. http://www.colpos.mx/asyd/volumen5/numero1/asd-09-002.pdf.

José Luis Rocha. "Censo estadounidense 2010: cifras e implicaciones de la mayor presencia de centroamericanos en Estados Unidos". Revista Académica de la Universidad Centroamericana. Encuentro. 2011.

Keohane, Robert y Joseph Nye (1988). Poder e interdependencia: La politica mundial en transición. Buenos Aires. Grupo Editor Latinoamericano, p. 15.

Paul Bohannan, Mark Glazer. Antropología. 1993. 2. Edición. Editorial McGraw-Hill, España.

Iain Chambers. Migración, Cultura, Identidad. 1994. Buenos Aires. Amorrortu editores, pág. 19.

Richard Pells. “¿Existe el McMundo?”. Dossier 5. http://www.istor.cide.edu/ archivos/num 11/dossier5.pdf

Joaquín Arango. Las "leyes de las migraciones" De e. G. Ravenstein, Cien años después. http://reis.cis.es/REIS/PDF/REIS_032_03.pdf

"Theories of International Migration: A Review and Appraisal". http://www. jstor.org/stable/2938462 




"Abstracción"

Medidas: 143 x $104 \mathrm{cms}$

Técnica: mixta

Año: 2013 